was 34 years, for women 32 years. 20\% were head injuries, 33\% fractures, higher than average fracture rate in all injuries. 80 injuries were serious (AIS 3), 8 severe (AIS 4) and 3 critical (AIS 5). $60 \%$ of the injured had used helmet, and got fewer head injuries than those without helmets. $10 \%$ were influenced by alcohol/ drugs. $77 \%(\mathrm{~N}=1673)$ happened in "inner" city, $13 \%$ in wooden areas in the city, $7 \%$ in other municipalities, and $3 \%$ abroad. In $10 \%(\mathrm{~N}=164)$ of injuries in "inner city", tram rails were involved. Police registered 125 bicycle injuries in "inner city" during 2014, 7\% of injuries treated at OUH. Since 2003, population of Oslo has increased by $22 \%$, bicycle injuries by $21 \%$.

Conclusions Incidence of bicycle injuries in the population of Oslo seems to be rather stable during the last 12 years. They are more severe than injuries in average. Patients without helmets have more head injuries than patients with helmets.

\section{CYCLING INFRASTRUCTURE FOR REDUCING CYCLING INJURIES IN CYCLISTS: A COCHRANE REVIEW}

${ }^{1}$ Caroline A Mulvaney, ${ }^{1}$ Sherie Smith, ${ }^{1}$ Michael C Watson, ${ }^{2}$ John Parkin, ${ }^{1}$ Carol Coupland, ${ }^{3}$ Phil Miller, ${ }^{1}$ Denise Kendrick, ${ }^{4}$ Hugh McClintock. ${ }^{1}$ University of Nottingham, UK; ${ }^{2}$ University of the West of England, UK; ${ }^{3}$ Nottingham University Hospitals NHS Trust, UK; ${ }^{4}$ Pedals, UK

\subsection{6/injuryprev-2016-042156.295}

Background Cycling infrastructure aims to make cycling more convenient and safer for cyclists. We undertook a Cochrane review to assess the effectiveness of cycling infrastructure at reducing cycling injuries in cyclists.

Methods Sixteen databases, twelve websites and conference proceedings were searched up to March 2015. Eligible studies included RCTs, CBAs or an ITS evaluating a cycling infrastructure and reporting injuries or collisions. Two authors independently extracted study data and quality assessment.

Results Twenty one studies met inclusion criteria. Meta-analyses relating to cycle lanes on roads (rate ratio (RR) 1.21, 95\% confidence interval (CI): 0.70 to 2.08 ) and cycle routes and networks (RR $0.68,95 \%$ CI: 0.31 to 1.47 ) found no evidence that either were effective at reducing cycle collisions. From a narrative review, there was some evidence that $20 \mathrm{mph}$ speed limits were effective at reducing collisions. Redesigning specific parts of cycle routes that may be particularly busy or complex in terms of traffic movement may reduce the risk of collision. The conversion of intersections with and without signals to roundabouts with cycle paths may reduce the odds of collision. Findings related to the instalment of Advanced Stop Lines, use of colour, cycle tracks and cycle paths suggest these neither reduce nor increase injury collisions in cyclists. There was some evidence that the conversion of intersections to roundabouts with cycle lanes marked as part of the circulating carriageway may increase cycle collisions. There was some evidence that continuing a cycle lane across the mouth of a side road with a give way line onto the main road may increase the risk of injury collisions in cyclists.

Conclusions Several designs of cycling infrastructure may reduce collisions. There is a paucity of high quality evaluations of cycling infrastructure. The use of adequate data collection periods and assessment of cycle flows would improve future evaluations.

\section{6 CYCLIST DEATHS IN LONDON: IMPLICATIONS FROM A SAFE SYSTEMS PERSPECTIVE}

${ }^{1}$ Nicola Christie, ${ }^{2}$ Rachel Talbot, ${ }^{2}$ Steve Reed, ${ }^{2}$ Jo Barnes, ${ }^{2}$ Pete Thomas. ${ }^{1}$ University College London, UK; ${ }^{2}$ Loughborough University, UK

\subsection{6/injuryprev-2016-042156.296}

Background In 2013 the London Mayor committed to increasing cycling levels by $400 \%$ (from 2001) by 2026 . Although the numbers of deaths per year are relatively low cycling in London has become highly politicised with significant media focus on every cycle death in the capital. This study was commissioned by Transport for London to explore contributory factors to cyclist deaths and implications for interventions.

Methods This study involved an in-depth case review of 53 pedal cycle fatalities in London between 2007-2011. Police fatal reports were used in the analysis. The method involved application of a Haddon matrix approach to data analysis and a case by case review by a multidisciplinary team to explore the multifactorial nature of contributory factors from a safe systems perspective.

Results Over half the crashes involved a truck ( $>3.5$ tonnes) as the primary collision partner, most happened during daylight and the commute period, on low speed $(30 \mathrm{mph})$ urban roads and at a junction, particularly at a complex junction. A notable finding was the involvement of trucks in fatalities, particularly for female cyclists, where the truck was turning left. For these crashes contributory factors were identified as poor visibility of the cyclist to the truck driver related to cab design and lack of mirrors, poor positioning by the cyclist and infrastructure issues such as lane narrowing creating a conflict point between cyclist and trucks.

Conclusions Potential countermeasures to mitigate risks for cyclists include the design of trucks to create greater visibility of vulnerable road users, training of both drivers and cyclists to raise awareness of visibility and designing infrastructure and managing traffic to reduce the opportunities of conflicts arising in the first place. Few well designed intervention studies were identified. The overrepresentation of female cyclists in collisions with left turning trucks is an issue that warrants further investigation.

\section{Alcohol, Drugs and Medicines}

\section{Parallel Tue 2.4}

\section{CONCURRENT USE OF ALCOHOL AND MARIJUANA AND FATAL MOTOR VEHICLE CRASHES: A CASE-CONTROL STUDY}

Guohua Li, Stanford Chihuri. Columbia University, USA

\subsection{6/injuryprev-2016-042156.297}

Background About one third of fatally injured drivers in the United States test positive for non-alcohol drugs and 20\% test positive for two or more drugs. Alcohol-marijuana is the most commonly detected poly-drug combination. The role of concurrent use of alcohol and marijuana in crash causation has not been well understood.

Methods Using a case-control design, we assessed the individual and joint effects of alcohol and marijuana on fatal crash risk. Cases $(n=2613)$ were drivers who were involved in fatal motor vehicle crashes in the continental United States during specific time periods in 2006, 2007, and 2008 and controls $(n=7719)$ 